\title{
Clostridium ljungdahlii sp. nov., an Acetogenic Species in Clostridial rRNA Homology Group I
}

\author{
RALPH S. TANNER, ${ }^{1 *}$ LETRISA M. MILLER, ${ }^{1}$ AND DECHENG YANG ${ }^{2}$ \\ Department of Botany and Microbiology, University of Oklahoma, Norman, Oklahoma 73019, ${ }^{1}$ and \\ Department of Microbiology, University of Illinois, Urbana, Illinois $61801^{2}$
}

\begin{abstract}
Clostridium ljungdahlii sp. nov. strain ATCC $49587^{\mathrm{T}}$ (T = type strain) was isolated from chicken yard waste for its ability to produce ethanol from synthesis gas. This gram-positive, motile, sporeforming rod's metabolism was primarily acetogenic. $C$. ljungdahlii grew with carbon monoxide, hydrogen and carbon dioxide, ethanol, pyruvate, arabinose, xylose, fructose, or glucose. Methanol, ferulic acid, lactate, galactose, and mannose did not support growth. The G+C content was 22 to $23 \mathrm{~mol} \%$. C. ljungdahlii is the first acetogen in clostridial $23 \mathrm{~S}$ rRNA homology group I.
\end{abstract}

The potential for microbial production of liquid fuels (e.g. ethanol) and commodity chemicals (e.g., acetic acid) from synthesis gas $\left(\mathrm{CO}-\mathrm{H}_{2}-\mathrm{CO}_{2}\right)$ derived from coal has been recognized (27) and has prompted investigations of microorganisms which can metabolize the components of synthesis gas under anoxic conditions. A strain which could produce ethanol from synthesis gas was isolated from chicken yard waste $(2,25)$. In this report we describe this strain, a new, anaerobic, gram-positive, spore-forming rod which is the first acetogenic species in clostridial rRNA group I, as described by Johnson and Francis (15).

(A portion of this work has appeared previously [24].)

\section{MATERIALS AND METHODS}

The acetogenic clostridium described here was isolated by Sudhakar Barik at the University of Arkansas from an enrichment inoculated with chicken yard waste at an initial $\mathrm{pH}$ of 5.0 and incubated at $37^{\circ} \mathrm{C}$ under an atmosphere of synthesis gas $\left(\mathrm{CO}-\mathrm{H}_{2}-\mathrm{CO}_{2}-\mathrm{CH}_{4}, 73: 15: 10: 2\right)(2)$. This isolate was named Clostridium ljungdahlii. The single strain was designated strain PETC $^{\mathrm{T}}$ ( $\mathrm{T}=$ type strain) and was deposited in the American Type Culture Collection as strain ATCC $49587^{\mathrm{T}}$.

Media. The media used for routine growth and characterization experiments were prepared by using strict anoxic techniques (1) and contained (per liter) $1.0 \mathrm{~g}$ of $\mathrm{NH}_{4} \mathrm{Cl}, 0.8 \mathrm{~g}$ of $\mathrm{NaCl}, 0.1 \mathrm{~g}$ of $\mathrm{KCl}, 0.1 \mathrm{~g}$ of $\mathrm{KH}_{2} \mathrm{PO}_{4}, 0.2 \mathrm{~g}$ of $\mathrm{MgSO}_{4} \cdot 7 \mathrm{H}_{2} \mathrm{O}, 0.02 \mathrm{~g}$ of $\mathrm{CaCl}_{2} \cdot 2 \mathrm{H}_{2} \mathrm{O}, 1.0 \mathrm{~g}$ of $\mathrm{NaHCO}_{3}$, $1.0 \mathrm{~g}$ of yeast extract (Difco Laboratories, Detroit, Mich.), $0.2 \mathrm{~g}$ of cysteine hydrochloride, $0.2 \mathrm{~g}$ of $\mathrm{Na}_{2} \mathrm{~S} \cdot 9 \mathrm{H}_{2} \mathrm{O}, 10 \mathrm{ml}$ of a trace metal solution (22), and $10 \mathrm{ml}$ of a vitamin solution (22). An atmosphere containing $\mathrm{N}_{2}$ and $\mathrm{CO}_{2}$ (80:20, pressurized to $70 \mathrm{kPa}$ ) was used for growth with organic substrates, which were added to a final concentration of $5 \mathrm{~g} / \mathrm{liter}$. $\mathrm{H}_{2}-\mathrm{CO}_{2}(80: 20$, pressurized to $200 \mathrm{kPa})$ or $\mathrm{CO}-\mathrm{N}_{2}-\mathrm{CO}_{2}$ (75:20:5, pressurized to $140 \mathrm{kPa}$ ) was used for growth on gaseous substrates. The initial medium $\mathrm{pH}$ was 5.8 to 5.9 . Cultures were incubated at $37^{\circ} \mathrm{C}$. The optimum $\mathrm{pH}$ (initial $\mathrm{pH})$ was determined in medium containing fructose as the substrate and sodium acetate, 2 - $(N$-morpholino)ethanesulfonic acid (MES), or $N$-tris(hydroxymethyl)methyl-2-aminoethanesulfonic acid (TES) (Sigma Chemical Co., St. Louis,

\footnotetext{
* Corresponding author.
}

Mo.) as a buffer (1.0 g/liter). The optimum temperature for growth was determined by using fructose as the substrate.

Fermentation balance. A fermentation balance was determined for growth on fructose or $\mathrm{H}_{2}-\mathrm{CO}_{2}$. Fructose was measured by using a phenol-sulfuric acid carbohydrate assay (9). Utilization of $\mathrm{H}_{2}-\mathrm{CO}_{2}(80: 20)$ was determined by using a pressure transducer system (8) to measure the reduction of gas pressure in sealed culture tubes (1). Individual gases were measured with a gas chromatograph equipped with a thermal conductivity detector (Varian, Sugar Land, Tex.) and a Porapak Super Q column (Alltech, Deerfield, Ill.). The following equation was used to calculate the amount of gas consumed: $4 \mathrm{H}_{2}+2 \mathrm{CO}_{2} \rightarrow \mathrm{CH}_{3} \mathrm{COOH}+2 \mathrm{H}_{2} \mathrm{O}$ (19). Acetic acid was measured by ion-exclusion high-performance liquid chromatography on an Aminex HPX-87H column (Bio-Rad, Richmond, Calif.). Ethanol was measured enzymatically with alcohol dehydrogenase (kit 332-B; Sigma) or by gas chromatography on a GP $10 \% \mathrm{SP}-1200 / 1 \% \mathrm{H}_{3} \mathrm{PO}_{4}$ Chromsorb WAW column (Supelco, Inc., Bellefonte, $\mathrm{Pa}$.).

Electron microscopy. Cells of fructose- or $\mathrm{H}_{2}-\mathrm{CO}_{2}$-grown C. ljungdahlii were allowed to settle onto carbon-coated Formvar film on copper electron microscope grids. For whole-cell transmission electron microscopy, cells were fixed with glutaraldehyde or left untreated and then negatively stained with phosphotungstic acid or uranyl acetate or left unstained. Electron micrographs were obtained with a Zeiss model EM-10 transmission electron microscope. Energy-dispersive spectroscopy (12) of unstained fructose- or $\mathrm{H}_{2}-\mathrm{CO}_{2}$-grown cells was performed with a JOEL model 2000 transmission electron microscope equipped with a Delta 4 Quantum thin-window X-ray detector (Kevex, San Carlos, Calif.).

16S rRNA sequence analysis. Cells of Clostridium barkeri ATCC 25849, Clostridium lituseburense ATCC 25759, Clostridium pasteurianum ATCC 6013, and Clostridium tyrobutyricum ATCC 25755 were provided by John L. Johnson. The 16S rRNA sequences of $C$. barkeri, $C$. lituseburense, $C$. ljungdahlii, $C$. pasteurianum, and $C$. tyrobutyricum were determined in the laboratory of Carl R. Woese $(17,20)$. The 16S rRNA sequences of Bacillus subtilis and Escherichia coli have been published previously $(3,13)$. Sequences were analyzed by a distance matrix analysis by using a program for fitting trees to distance matrix data, as adapted by workers in the laboratory of Carl R. Woese $(7,16,20)$.

Analytical procedures. Growth was determined by measuring turbidity in aluminum seal tubes (1). DNA from $C$. ljungdahlii was purified, and the $\mathrm{G}+\mathrm{C}$ content was deter- 


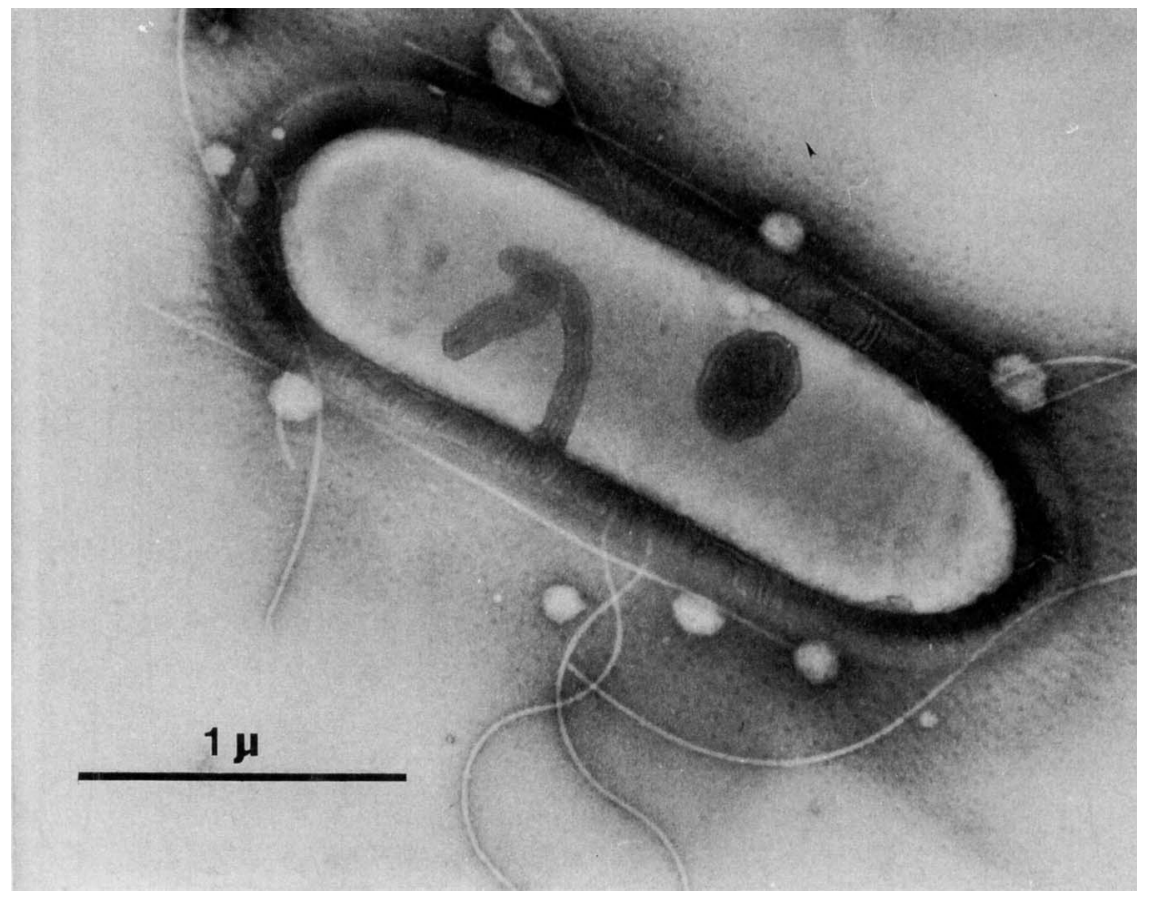

FIG. 1. Transmission electron micrograph of $C$. ljungdahlii. Cells were spread on a carbon-coated Formvar grid and negatively stained with $1 \%$ phosphotungstic acid (pH 7). The micrograph was taken with a Zeiss model EM-10 transmission electron microscope.

mined from the melting temperature by using a Beckman model DU-8B spectrophotometer equipped with a melting temperature module (14). Indole production and esculin hydrolysis were determined by using standard assays (21).

Nucleotide sequence accession numbers. The nucleotide sequences of $C$. barkeri, $C$. lituseburense, $C$. ljungdahlii, $C$. pasteurianum, and $C$. tyrobutyricum were deposited in the GenBank library under accession numbers M23927, M59107, M59097, M23930, and M59113, respectively.

\section{RESULTS AND DISCUSSION}

Cellular morphology. Electron and phase-contrast microscopy revealed that cells of $C$. ljungdahlii were motile, straight rods ( 0.6 by 2 to $3 \mu \mathrm{m})$ occurring mostly as single cells (Fig. 1). Spores were rarely observed; terminal to subterminal nonswelling structures tentatively identified as forespores were observed infrequently. Cells were peritrichous and had a thick $(0.1-$ to $0.2-\mu \mathrm{m})$ coat of material of unknown composition surrounding each cell. Electron microscopy of $C$. ljungdahlii was problematic. The majority of cells in unstained or stained specimens that were not fixed or were fixed with glutaraldehyde were electron opaque. Energy-dispersive spectroscopy (Fig. 2) indicated that these electron-opaque cells contained calcium, as shown by the $\mathrm{X}$-ray peaks at $3.7 \mathrm{keV}\left(\mathrm{K} \alpha_{1}\right)$ and $4.0 \mathrm{keV}$ (K edge) (12). The calcium was probably associated with the cell envelope, since lysed cells also were frequently opaque to transmission electron microscopy (data not shown).

Physiology. C. ljungdahlii grew autotrophically with $\mathrm{H}_{2}-$ $\mathrm{CO}_{2}$ or $\mathrm{CO}$ and used a number of organic compounds, including ethanol, pyruvate, and some simple carbohydrates, as carbon and energy sources (Table 1). Growth on formate was poor. Cultures partially metabolized malate, as indicated by a $\mathrm{pH}$ change in the medium after incubation with this substrate. Improved control of culture $\mathrm{pH}$ near the optimum value (see below) might result in better growth of C. ljungdahlii with formate or malate. Methanol, even when tested at a concentration of $1 \mathrm{~g} /$ liter, as well as the methoxylated compounds ferulic acid and trimethoxybenzoate, did not support growth.

Addition of a vitamin solution (22) was required for growth of $C$. ljungdahlii. Addition of yeast extract $(1 \mathrm{~g} /$ liter $)$ or Casamino Acids ( $2 \mathrm{~g} /$ liter) was also required for reliable, reproducible growth. The exact nutritional requirements of C. ljungdahlii were not determined.

The optimum initial culture $\mathrm{pH}$ for growth was 6.0; the initial culture $\mathrm{pH}$ range at which growth occurred was 4.0 to 7.0. A final $\mathrm{pH}$ of 3.9 to 4.1 was obtained when $C$. ljungdahlii was cultured in unbuffered media. The optimum temperature for growth was $37^{\circ} \mathrm{C}$; the growth temperature range was 30 to $40^{\circ} \mathrm{C}$. Under the optimal $\mathrm{pH}$ and temperature conditions, a doubling time of $0.26 \mathrm{~h}^{-1}$ was obtained for growth with either fructose or $\mathrm{H}_{2}-\mathrm{CO}_{2}$.

Cultures of $C$. ljungdahlii quantitatively converted $4 \mathrm{mmol}$ of hydrogen and $2 \mathrm{mmol}$ of carbon dioxide into $1 \mathrm{mmol}$ of acetic acid or $1 \mathrm{mmol}$ of fructose into $2.44 \mathrm{mmol}$ of acetic acid; no other end products of metabolism were detected in these experiments. The fermentation balances demonstrate that $C$. ljungdahlii is an acetogen, a bacterium which can synthesis acetate from one-carbon compounds (19). Most acetogens quantitatively convert carbohydrates to acetate: 1 hexose $\rightarrow 3$ acetic acid. The conversion by $C$. ljungdahlii of 1 fructose molecule to 2.44 acetate molecules is similar to the yields of acetate observed for other acetogens: 2.1 to 2.3 acetate molecules per hexose molecule for Acetobacterium carbinolicum (10); 2.2 to 2.8 acetate molecules per fructose molecule for Acetobacterium woodii in media supplemented with yeast extract and/or Trypticase (22a); 2.3 to 3.0 (average, 2.5) acetate molecules per glucose molecule for Acetogenium kivui (18); an average of 2.55 acetate molecules per 


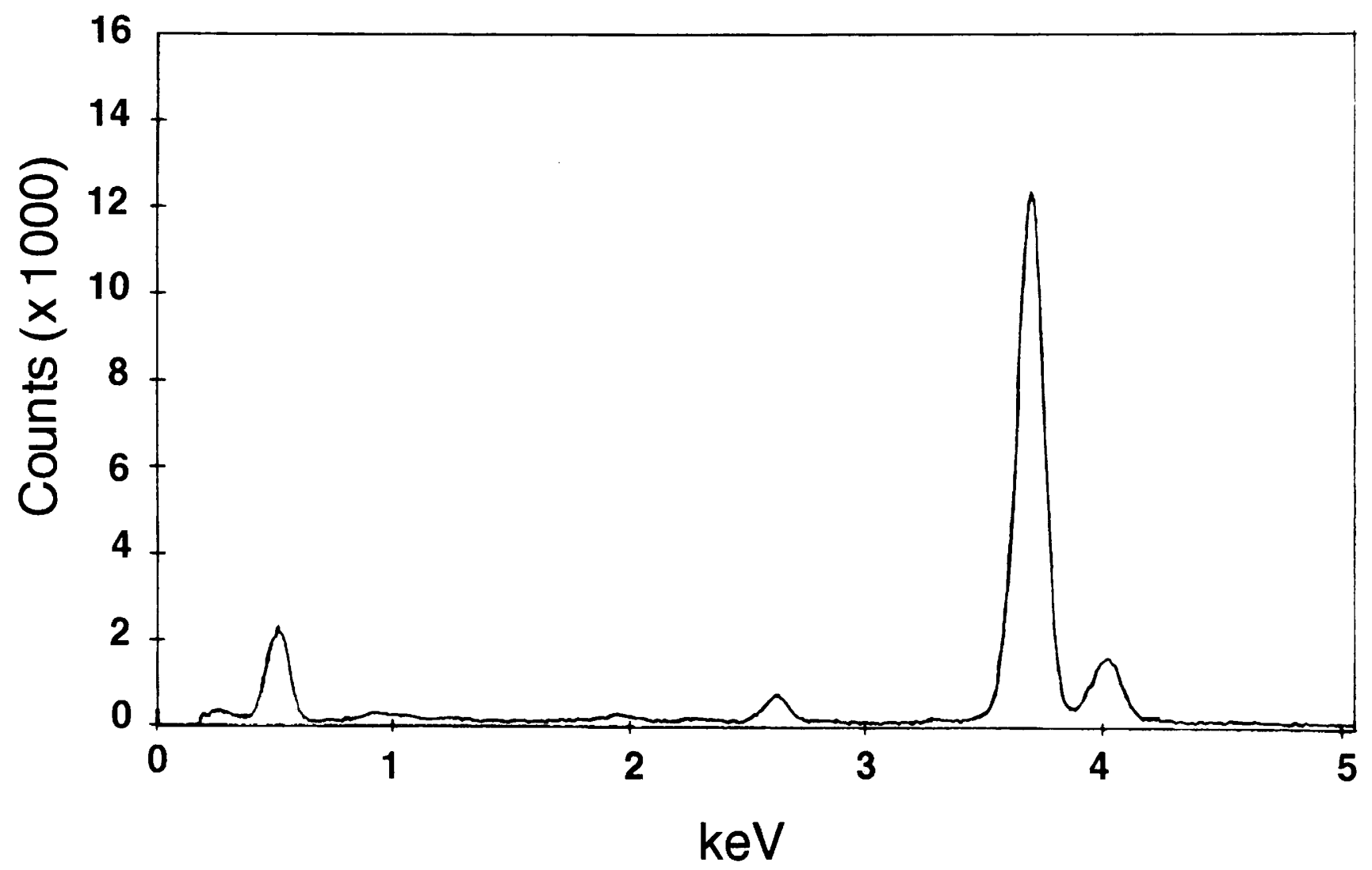

FIG. 2. X-ray spectrum from a cell of $C$. ljungdahlii.

TABLE 1. Substrate utilization by $C$. ljungdahlii

\begin{tabular}{|c|c|c|c|}
\hline Substrate $^{a}$ & Result $t^{b}$ & Substrate & Result \\
\hline $\mathrm{H}_{2}-\mathrm{CO}_{2}$ & + & Ribose & + \\
\hline $\mathrm{CO}$ & + & Xylose & + \\
\hline Sodium formate & $+1-$ & Glucose & $+^{d}$ \\
\hline Methanol & - & Fructose & + \\
\hline Ethanol & + & Galactose & - \\
\hline Sodium pyruvate & + & Mannose & - \\
\hline Sodium lactate & - & Sorbitol & - \\
\hline Glycerol & - & Sucrose & - \\
\hline Sodium citrate & - & Lactose & - \\
\hline Sodium succinate & - & Maltose & - \\
\hline Sodium fumarate & + & Starch & - \\
\hline Malic acid & $-c$ & Ferulic acid & - \\
\hline Erythrose & + & Trimethoxybenzoic acid & - \\
\hline Threose & + & Casamino Acids & $+1-$ \\
\hline Arabinose & + & Alanine & - \\
\hline
\end{tabular}

${ }^{a}$ Each substrate was tested for the ability to support growth of $C$. ljungdahlii. Gaseous substrates were added to the gas phase of a crimp-sealed tube. Other substrates were added at a concentration of $5 \mathrm{~g} /$ liter to a medium containing $1 \mathrm{~g}$ of yeast extract per liter. A $2 \%$ inoculum of fructose-grown cells was used; no growth or poor growth results were confirmed by using $\mathrm{H}_{2}-\mathrm{CO}_{2}$-grown cells as an inoculum.

${ }^{b}$ Growth was measured in each aluminum seal tube (1). Levels of growth (compared with the control) were scored as follows:,$+ A_{600}$ of $>0.1 ;+/-$, $A_{600}$ between 0.1 and 0.01 ; and,$- A_{600}$ of $<0.01$.

${ }^{c}$ Malate was metabolized by $C$. ljungdahlii, as indicated by a change in the culture $\mathrm{pH}$.

${ }^{d}$ Cultures grown previously on fructose or $\mathrm{H}_{2}-\mathrm{CO}_{2}$ required adaptation for growth on glucose. glucose molecule for Clostridium thermoaceticum (11); and 2.5 acetate molecules per glucose molecule for Clostridium thermoautotrophicum (26). When, examined, the balance of the hexose utilized was converted into cell mass (10). In the strictest sense, an acetogen is a bacterium that uses the Wood-Ljungdahl pathway to reduce $\mathrm{CO}_{2}$ to acetate (19). The quantitative conversion of $\mathrm{CO}_{2}$ and $\mathrm{H}_{2}$ to acetic acid by $C$. ljungdahlii is consistent with the probability that this organism possesses this pathway.

Cultures of $C$. ljungdahlii, which was isolated for its ability to convert synthesis gas to ethanol $(2,25)$, often have 0 to $2 \mathrm{mM}$ ethanol present as an end product of metabolism. The ability to both produce and consume ethanol has been observed in other acetogens (specifically, in species of the genus Acetobacterium) (4). Cultures may also produce 0 to $0.3 \mathrm{CO}_{2}$ molecule per fructose molecule fermented. Vega et al. (25) noted that $C$. ljungdahlii produced trace amounts of $\mathrm{CO}_{2}$ when it fermented fructose and produced $\mathrm{CO}_{2}$ and traces of $\mathrm{H}_{2}$ when it metabolized $\mathrm{CO}$.

Cultures did not hydrolyze esculin and produced indole from tryptophan.

Phylogeny. The phylogenetic relationship of $C$. ljungdahlii to other clostridia is shown in Fig. 3. C. ljungdahlii was found to be closely related to $C$. tyrobutyricum, which ferments carbohydrates to butyrate and acetate (5). $C$. ljungdahlii is a member of clostridial 23S rRNA homology group I; the 16S rRNA sequence analysis clustered $C$. ljungdahlii with two other group I clostridia, C. pasteurianum and $C$. tyrobutyricum. $C$. lituseburense is a species in clostridial rRNA homology group II, and $C$. barkeri is a representative of the clostridia whose DNAs have compar- 


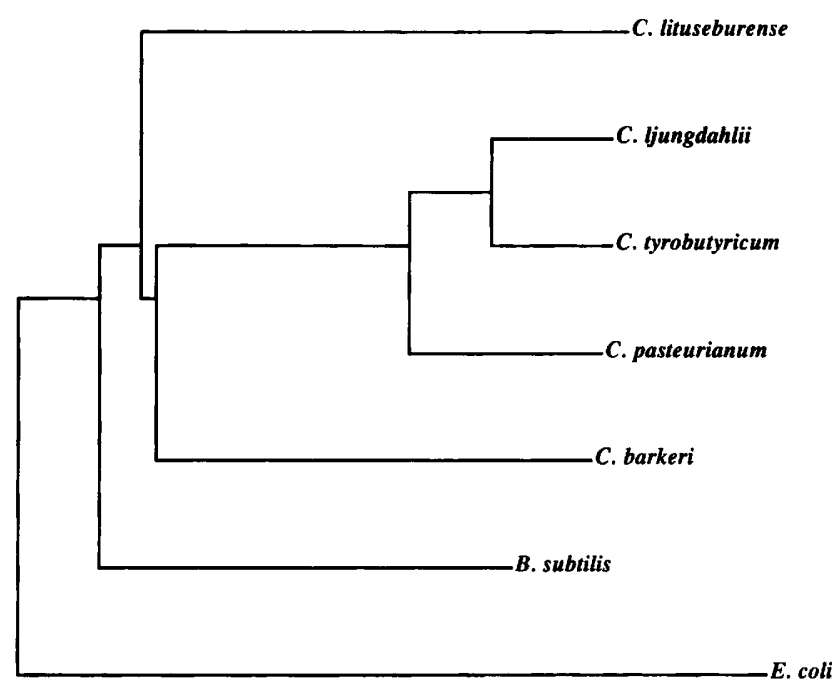

FIG. 3. Phylogeny of $C$. ljungdahlii as determined from a $16 \mathrm{~S}$ rRNA sequence analysis. The total horizontal distance between two species indicates the difference between their sequences. The bar indicates a distance corresponding to a $5 \%$ difference.

atively high $\mathrm{G}+\mathrm{C}$ contents and which do not belong to either rRNA homology group, as described by Johnson and Francis (15). C. ljungdahlii is the first known acetogen in clostridial rRNA homology group I. The phylogeny of six other acetogens (Acetobacterium woodii, Acetogenium kivui, Clostridium aceticum, Clostridium formicoaceticum, C. thermoaceticum, and Eubacterium limosum) was examined by $16 \mathrm{~S}$ rRNA oligonucleotide cataloging, which showed that none of these species belonged to either homology group I or group II of the clostridia (23). A more recent examination of the phylogeny of the clostridia, including the rRNA homology groups, has been published (6).

C. ljungdahlii's DNA had a $\mathrm{G}+\mathrm{C}$ content of 22 to 23 mol\%, as determined by the melting temperature method. Clostridium putrefaciens is another clostridium with a very low $\mathrm{G}+\mathrm{C}$ content ( 22 to $25 \mathrm{~mol} \%$ ) reported for its DNA (5). This $\mathrm{G}+\mathrm{C}$ content is significantly lower than the $\mathrm{G}+\mathrm{C}$ contents reported for other acetogens (19).

Phenotypically, $C$. ljungdahlii is distinguishable from most clostridia since its metabolism is basically acetogenic. $C$. ljungdahlii is phenotypically distinct from other acetogens as follows $(5,19)$ : from Acetogenium kivui, $C$. thermoaceticum, and $C$. thermoautotrophicum, which are thermophiles; from Acetobacterium carbinolicum, Acetobacterium woodii, $C$. formicoaceticum, $C$. thermoaceticum, $C$. thermoautotrophicum, and Eubacterium limosum, which can grow with methanol; from $C$. formicoaceticum and Clostridium magnum, which do not grow with $\mathrm{H}_{2}-\mathrm{CO}_{2}$; from $C$. thermoaceticum and Eubacterium limosum, which are not motile; from Acetobacterium carbinolicum, Acetobacterium wieringae, and Acetobacterium woodii, which can grow with lactate; and from $C$. aceticum, whose $\mathrm{pH}$ optimum is 8.3. The optimum growth $\mathrm{pH}$ is lower than that reported for most acetogens (19); only $C$. thermoautotrophicum has a lower reported optimum $\mathrm{pH}$ ( $\mathrm{pH}$ 5.7).
C. ljungdahlii is the first known acetogenic member of rRNA homology group I, which includes solvent-producing species, such as Clostridium acetobutylicum, Clostridium beijerinckii, and Clostridium butyricum $(5,15)$. A comparative biochemical study of these species could be helpful for improving the conversion of synthesis gas to ethanol catalyzed by $C$. ljungdahlii $(2,25)$.

Description of Clostridium ljungdahlii sp. nov. Clostridium ljungdahlii (ljung.dahl'i.i. M.L. gen. n. ljungdahlii, of Ljungdahl, in recognition of Lars G. Ljungdahl's research contributions in both the study of acetogens and the study of clostridia). Cells are gram-positive, motile rods ( 0.6 by 2 to 3 $\mu \mathrm{m})$ and occur mostly singly. Cells rarely sporulate. Growth occurs only under anoxic conditions. The optimum temperature and initial $\mathrm{pH}$ for growth are $37^{\circ} \mathrm{C}$ and 6.0 , respectively.

Grows autotrophically with $\mathrm{H}_{2}-\mathrm{CO}_{2}$ or $\mathrm{CO}$ and chemoorganotrophically with formate, ethanol, pyruvate, fumarate, erythrose, threose, arabinose, xylose, glucose, and fructose. Methanol, ferulate, trimethoxybenzoate, lactate, glycerol, citrate, succinate, galactose, mannose, sorbitol, sucrose, lactose, maltose, and starch are not utilized. Acetic acid is the major end product of metabolism; traces of ethanol may also be produced.

The $\mathrm{G}+\mathrm{C}$ content of the DNA is 22 to $23 \mathrm{~mol} \%$ (as determined by the melting temperature method). A member of clostridial 23S rRNA homology group I, as determined by 16S rRNA sequence analysis.

The type strain, strain PETC, was isolated from chicken yard waste and has been deposited in the American Type Culture Collection as strain ATCC 49587.

\section{ACKNOWLEDGMENTS}

We thank Sudhakar Barik, who originally isolated C. ljungdahlii, Ellen Johnson, and E. C. Clausen for their interest and assistance. We also thank John L. Johnson for providing some of the clostridial tissues used in this study and Carl R. Woese for the 16S rRNA sequence analysis. Greg Strout and Scott Russell at the Samuel Roberts Noble Laboratory of Electron Microscopy were instrumental in the electron microscopy work. We also thank Bill Lorowitz for helpful discussions.

Part of this work was supported by contract DE-AC22-85PC80012 from the U.S. Department of Energy (to E. C. Clausen) and grant BSR-87-05352 from the National Science Foundation (to C. R. Woese).

\section{REFERENCES}

1. Balch, W. E., and R. S. Wolfe. 1976. New approach to the cultivation of methanogenic bacteria: 2-mercaptoethanesulfonic acid (HS-CoM)-dependent growth of Methanobacterium ruminantium in a pressurized atmosphere. Appl. Environ. Microbiol. 32:781-791.

2. Barik, S., S. Prieto, S. B. Harrison, E. C. Clausen, and J. L. Gaddy. 1988. Biological production of alcohols from coal through indirect liquefaction. Appl. Biochem. Biotechnol. 18: 363-378.

3. Brosius, J., J. L. Palmer, J. P. Kennedy, and H. F. Noller. 1978. Complete nucleotide sequence of a $16 \mathrm{~S}$ ribosomal RNA gene from Escherichia coli. Proc. Natl. Acad. Sci. USA 75:48014805.

4. Buschhorn, H., P. Durre, and G. Gottschalk. 1989. Production and utilization of ethanol by the homoacetogen Acetobacterium woodii. Appl. Environ. Microbiol. 55:1835-1840.

5. Cato, E. P., W. L. George, and S. M. Finegold. 1986. Genus Clostridium, p. 1141-1200. In P. H. A. Sneath, N. S. Mair, M. E. Sharpe, and J. G. Holt (ed.), Bergey's manual of systematic bacteriology, vol. 2. Williams \& Wilkins, Baltimore.

6. Cato, E. P., and E. Stackebrandt. 1989. Taxonomy and phylogeny, p. 1-26. In N. P. Minton and D. J. Clarke (ed.), Clostridia. Plenum Press, New York. 
7. De Soete. 1983. A least squares algorithm for fitting additive trees to proximity data. Psychometrika 48:621-626.

8. DeWeerd, K. A., F. Concannon, and J. M. Suflita. 1991. Relationship between hydrogen consumption, dehalogenation, and the reduction of sulfur oxyanions by Desulfomonile tiedjei. Appl. Environ. Microbiol. 57:1929-1934.

9. Dubois, M., K. A. Gilles, J. K. Hamilton, P. A. Rebers, and F. Smith. 1956. Colorimetric method for determination of sugars and related substances. Anal. Chem. 28:350-356.

10. Eichler, B., and B. Schink. 1984. Oxidation of primary aliphatic alcohols by Acetobacterium carbinolicum sp. nov., a homoacetogenic anaerobe. Arch. Microbiol. 140:147-152.

11. Fontaine, F. E., W. H. Peterson, E. McCoy, M. J. Johnson, and G. J. Ritter. 1942. A new type of glucose fermentation by Clostridium thermoaceticum n. sp. J. Bacteriol. 43:701-715.

12. Goldstein, J. I., D. E. Newbury, P. Echlin, D. C. Joy, C. Fiori, and E. Lifshin. 1981. Scanning electron microscopy and X-ray microanalysis. Plenum Press, New York.

13. Green, C. J., G. C. Stewart, M. A. Hollis, B. S. Vold, and K. F. Bott. 1985. Nucleotide sequence of Bacillus subtilis ribosomal RNA operon, $r m B$. Gene 37:261-266.

14. Johnson, J. L. 1981. Genetic characterization, p. 450-472. In P. Gerhardt, R. G. E. Murray, R. N. Costilow, E. W. Nester, W. A. Wood, N. R. Krieg, and G. B. Phillips (ed.), Manual of methods for general bacteriology. American Society for Microbiology, Washington, D.C.

15. Johnson, J. L., and B. S. Francis. 1975. Taxonomy of the clostridia: ribosomal ribonucleic acid homologies among the species. J. Gen. Microbiol. 88:229-244.

16. Jukes, T. H., and C. R. Cantor. 1969. Evolution of protein molecules, p. 21-132. In H. N. Munro (ed.), Mammalian protein metabolism. Academic Press, Inc., New York.

17. Lane, D. J., B. Pace, G. J. Olsen, D. A. Stahl, M. L. Sogin, and N. R. Pace. 1985. Rapid determination of 16 S ribosomal RNA sequences for phylogenetic analysis. Proc. Natl. Acad. Sci. USA 82:6955-6959.
18. Leigh, J. A., F. Mayer, and R. S. Wolfe. 1981. Acetogenium kivui, a new thermophilic hydrogen-oxidizing, acetogenic bacterium. Arch. Microbiol. 129:275-280.

19. Ljungdahl, L. G. 1986. The autotrophic pathway of acetate synthesis in acetogenic bacteria. Annu. Rev. Microbiol. 40:415450.

20. Oyaizu, H., B. Debrunner-Vossbrink, L. Mandelco, J. A. Studier, and C. R. Woese. 1987. The green non-sulfur bacteria: a deep branching in the eubacterial line of descent. Syst. Appl. Microbiol. 9:47-53.

21. Smibert, R. M., and N. R. Krieg. 1981. General characterization, p. 409-443. In P. Gerhardt, R. G. E. Murray, R. N. Costilow, E. W. Nester, W. A. Wood, N. R. Krieg, and G. B. Phillips (ed.), Manual of methods for general bacteriology. American Society for Microbiology, Washington, D.C.

22. Tanner, R. S. 1989. Monitoring sulfate-reducing bacteria: comparison of enumeration media. J. Microbiol. Methods 10:83-90. 22a.Tanner, R. S. Unpublished data.

23. Tanner, R. S., E. Stackebrandt, G. E. Fox, R. Gupta, L. J. Magrum, and C. R. Woese. 1982. A phylogenetic analysis of anaerobic eubacteria capable of synthesizing acetate from carbon dioxide. Curr. Microbiol. 7:127-132.

24. Tanner, R. S., and D. Yang. 1990. Clostridium ljungdahlii PETC sp. nov., a new, acetogenic, gram-positive anaerobic bacterium, abstr. R-21, p. 249. Abstr. 90th Annu. Meet. Am. Soc. Microbiol. 1990. American Society for Microbiology, Washington, D.C.

25. Vega, J. L., S. Prieto, B. B. Elmore, E. C. Clausen, and J. L. Gaddy. 1989. The biological production of ethanol from synthesis gas. Appl. Biochem. Biotechnol. 20/21:781-797.

26. Wiegel, J., M. Braun, and G. Gottschalk. 1981. Clostridium thermoautotrophicum species novum, a thermophile producing acetate from molecular hydrogen and carbon dioxide. Curr. Microbiol. 5:255-260.

27. Zeikus, J. G. 1980. Chemical and fuel production by anaerobic bacteria. Annu. Rev. Microbiol. 34:423-464. 